\title{
A Longitudinal Study about Stress, Burnout and \\ Coping
}

\author{
Helena de Almeida \\ University of Algarve, Campus de Gambelas, 8005-139 Faro \\ Portugal
}

Accepted: July 05, 2013 Published: August 17, 2013

Doi:10.5296/ijhrs.v3i2.4136

URL: http://dx.doi.org/10.5296/ijhrs.v3i2.4136

\begin{abstract}
A longitudinal study was completed ( $\mathrm{T}$ and $\mathrm{T}+10$ years) that aimed to evaluate the evolution of Stress levels and to identify Psychologists' Coping Strategies in the Algarve (south of Portugal). The sample used in this field study was comprised of 70 psychologists at the moment $\mathrm{T}$ and 63 at the moment $\mathrm{T}+10$ years. The followed methodology consisted of descriptive statistics and simple regression equations using the SPSS v17.0 software. The results show some significant differences between the two evaluated moments ( $\mathrm{T}$ and $\mathrm{T}+10$ years) at Stress and Burnout level. However, at both evaluation moments ( $\mathrm{T}$ and $\mathrm{T}+10$ years), the Coping strategies used more by the evaluated psychologists were the control strategies and the ones they found more effective were the symptoms management. These results have major implications both for the psychologists and for the organizations for which they work. Key-words: Stress, Burnout, Coping, Psychologists.
\end{abstract}

\section{Occupational stress}

Occupational stress can be defined by the organizational stressors - work related factors and their complexities that go beyond the confront capacity of the individual and/or physiological, psychological and behavioural responses to tension in work situations (Jex, 1998; Jones \& Kinoman, 2001). These organizational stressors, also known as Stress determinant factors, have been particularly studied by several authors (Cooper \& Marchal, 1977; Beehr \& Mcgrath, 1996; Mcgrath \& Beer, 1990, et al.). Among them, and in our opinion, the Stress Factors Model by Cooper and Marchal (1977) is the one that looks the best to use in this article. These two authors conducted extensive research to identify the main factors which may be the origin of Occupational Stress. A first potential Stress factor emerges from the intrinsic aspects of work, in other words, the qualitative overload (task difficulty) or quantitative (excess) of work (Alvarez, 2003; Burden, 1988; Huberty \& Huebner, 1988; Manthei, 1987; Reiner \& Harstshore, 1982, et. al). A second Stress factor lies in the relations established with the supervisors, in questions related to the supervision. This factor is also identified in other studies (Burden, 1988; Reiner \& Harthore, 1982, et al.). Another Stress factor focuses on the role the worker performs in the organization (Cooper \& Smith, 2007; 
Huebner, 1992; Huebner \& Mills, 1997; Simons, 2006; Wise, 1985), who may feel the paper that was assigned to him is full of ambiguities, or there are role conflicts between him and other decisive workers in the organization. A fourth Stress factor may be associated to the opportunities given by the organization to open new perspectives to the worker, either monetary, social benefits, improvement opportunities and/or career progression (Schwab, Jackson \& Schuler, 1986, et. al). Another Stress factor is the perceived social support by the organization which works as a palliative between the worker and his superiors, subordinates and colleagues (Jackson, Schwab, \& Schuler (1986), et al). Another factor that may be part of the origin of Stress is the climate and organizational culture (Grant \& Langan-fox, 2007; Shell, 2007), namely, the way that an organization works and is designed might constrain the behaviour of the worker, limiting his action and his participation in the decision process. Another aspect that may be a potential Stress factor is the "home-work interface" which can lead to multiple problems: personal, familiar, financial, social or extra-professional. Given their valorative dimension, they are brought to work and have a negative impact on worker performance. In short, in the Cooper and Marchal conception, the relation established between the intrinsic aspects of work, the role performed in the organization, the development opportunities, the work relations, the climate and the organizational structure, the work-home interface and the worker, who has his personal characteristics tempered by his education and socialization, can be evaluated as a demand, which has a negative impact on performance.

No matter what the determinant factors are, the Occupational Stress is associated with negative consequences both for the individual and for the organization. There are writings that study the impact of the role of the stressors (for a revision see Bechr \& Glazer, 2005; Chang et al., 2005; Ortqvist \& Wincent, 2006).

\section{Burnout}

Burnout must be considered as an extension of occupational stress, as the result of a long-term process in which the worker feels that his resources to deal with the demands of his profession are exhausted (Maslach \& Schaufeli, 1993). No matter the definition or the conceptualization of Burnout, it must be very clear that this is the end of a long process and it is the result of the individual exposure to tensions and pressures of a work and occupational nature (Gomes \& Cruz, 2004). In the multi-dimensional perspective, Burnout is considered a subjective condition experienced by the individual as a response to chronic interpersonal stressors at work, integrating three dimensions (or components): emotional exhaustion, de-personalization and decreasing of personal accomplishment (Maslach, 1993; Maslach \& Jackson, 1986). Emotional Exhaustion describes the over solicitation or the depletion of the emotional, moral and psychological resources (Maroco \& Tecedeiro, 2009). De-personalization describes the dehumanization towards the other, branded by the disconnection, or "emotional dryness" (Delbrouck, 2006) which is similar to cynicism (suggested by Maslach), to his "raison d'être" of his professional activity (Maroco \& Tecedeiro, 2009). The decreasing of accomplishment shows the feeling of incapacity to do a good job, frustration, devaluation, guilt and demotivation at work and projects to change the job. As a consequence, the worker asks himself about his choice and his vocation for that 
particularly job (Delbrouck, 2006).

\section{Coping}

Coping, also known as "strategies to deal with", focus on different types of strategies. For instances, Folkman and Lazarus (1984) refer to the dichotomy approaching/separation, supporting the existence of two types of strategy: one is centred on the problem solving or "Instrumental Coping" (approaching), which consists of an attempt to modify the situation. An example of this strategy could be an attempt to make the boss change his mind about a plan of action and to make him follow it. Another strategy held by these authors focus on the regulation of the emotions (separation) as an attempt to decrease or eliminate Emotional Distress. This strategy relies on the regulation of the emotional state through the efforts that allow the individual to think and act in an effective way, by refusing a demand or a positive evaluation of a situation, for instance. Latak (1986), although proposing a slightly different perspective, refers to the same two functions of problem resolution and emotion regulation, distinguishing three types of strategies: Control, which consists of actions and proactive cognitive evaluations; Escape, based on actions and cognitions that suggest avoidance; and Symptoms Management, as a way of managing the symptoms connected to Occupational Stress, in general. Despite the expressed differences, the author states that the pro-active action strategies match the Coping categories centred on problem solving, and the avoidance type strategies match the Coping strategies that are centred on emotion regulation proposed by Lazarus and Folkman (1984), while introducing a third one - Symptoms Management that are associated with stressful life experiences.

\section{In health care relations: the psychologists}

In the health care jobs, also known as people in the helping professions or human service workers, including Health and Teaching jobs, Stress and Burnout are more frequent due to the intense and frequent contacts these workers have with the customers or students; for this reason, they are a specially affected professional group (Cordes \& Dougherty, 1993; Melo, Gomes \& Cruz, 1997; Payne \& Firth-Cozens et al, 1987.). In a general sense, the research that was done with psychologists show a group that lives in distress, while being a critical group inside the health care jobs that have been highly researched. For instance, Cruz, Gomes and Melo (2000) conducted a study with 439 Portuguese psychology professionals, and the results show that $30 \%$ come into contact with stress at work, $26.9 \%$ show emotional exhaustion, $7.1 \%$ depersonalization and $11.8 \%$ diminishing of personal accomplishment. Another study performed by Covolan $(1984,1996)$ with 84 psychologists shows that work overload is one of the determinant factors of emotional stress.

Rupert and Morgan (2005) conducted a study with 571 psychologists with doctoral degrees which shows the association between emotional exhaustion and less control over work, more working hours, more time spent on administrative and bureaucratic tasks, more negative behaviours in customers and patients' attendances. On the other hand, Wilkerson (2009), in a study with 482 school counsellor psychologists, found that Occupational Stress and the following burnout can be conditioned by the coping strategies employed by the individuals. Volker and collaborators (2009), in a study with 383 workers of the drug addiction support 
care, found that if active Coping is used more (problem solving), personal accomplishment is higher and if passive Coping (escape) is used more, emotional exhaustion and depersonalization are higher. In a general manner, the studies performed with psychologists do not show matching values, balancing the distress among them between 10 and $35 \%$. These results are of concern because they show that a large percentage of psychologists who live in distress use less adaptive coping strategies. Regarding the stress determinant factors, some authors support work overload (Burden, 1988; Gomes \& Cruz, 1999; Manthei, 1987, et al), others stand for the lack of supervision (Burden, 1988, Gomes \& Cruz 1999; Reiner \& Hartshore, 1982, et al.) and others endorse the problems and interpersonal conflicts in the workplace among co-workers and supervisors (Boice \& Meyers, 1987; Huebner, 1992; Huebener \& Mills, 1977; Manthei, 1987; Wise, 1985, among others).

\section{Research questions}

Following our discussion and thoughts centred on the Stress, Burnout and Coping concepts, the definition of the main research questions are now presented, as well the explanation of the methodological concept used in the experimental study:

- Which are the experimented Stress and Burnout levels?

- What kind of Stress factors do psychologists face in their activity?

- What are the most used Coping strategies?

- Which are the most effective Coping strategies to deal with Stress?

\section{Instruments}

The first instrument that was used was a stress questionnaire called "Psychology Professionals Stress Questionnaire" which evaluates stress factors in psychology professionals, regardless of their field of activity. It was developed by Cruz and Melo (1996), and it is materialised by 67 items which evaluate the potential origins of stress that can be answered on a 6 points Likert scale: (0, no stress; 5 , a lot of stress). The second instrument is the Maslach Burnout Inventory (MBI). It is a translated version of the Maslach Burnout Inventory (Maslach \& Jackson, 1986; Cruz, 1993; Cruz \& Melo, 1996). It is a self-registration instrument with 22 items and three scales (never, 0; many times, 5): emotional exhaustion (9 items), depersonalization (5 items) and personal accomplishment (8 items). The values above 2.6 in the emotional exhaustion dimension and above 1.8 in depersonalization are indicators of high levels of Burnout. The same happens with values lower than 3.5 in the personal accomplishment dimension (in this dimension higher values are indicators of lower Burnout). The third instrument is the adaptation done by Jesus and Pereira (1994) of the Latack Coping Strategies Scale (1986). This scale comprises 52 items: 17 of control, 11 of escape and 24 of symptoms management. The individual must answer on a 5 point scale (almost never do this, 1; almost always do this, 5)

7. Sample

The longitudinal study was done in two time frames: $\mathrm{T}$ and $\mathrm{T}+10$ moments. The $\mathrm{T}$ moment sample was formed by 70 individuals, with 52 females (74.3\%) and 18 males (25.7\%). 29 (41.4\%) subjects have a college degree in the health/clinical field, followed by 24 subjects $(34.3 \%)$ in the educational/scholar field and, lastly, by 17 subjects $(24.3 \%)$ in the 
social/organizational field. The average age is 33.57 years old, and, on average, they finished their college degree nine years ago, they have 8 years of work experience and have remained in their current position for 4.5 years. The 63 subjects surveyed in the $\mathrm{T}+10$ moment have an average age of 42 years, finished their college degree 16 years ago, have an average of 14 years of professional experience and have remained in their current position for 10 years.

\section{Procedure}

We personally contacted the organizations where the psychologists worked in the educational, re-educational, rehabilitation and health fields, all over the Algarve, and asked for permission to apply the questionnaires. After this step, all the objectives were individually explained, and the anonymity of the data assured. At last we individually applied all the questionnaires. Out of the 89 questionnaires applied in the T moment, 70 were filled, and out of the 70 applied in the $\mathrm{T}+10$ moment, 63 were filled. The high level of answers is due to having personal contact with the psychologists. A descriptive statistical methodology was used in the results analysis, using simple regression with the SPSS 17.0 software.

\section{Presentation of results}

\subsection{Stress Levels}

Table 1 shows the global levels of experienced stress by the psychologists from the Algarve, in the two evaluated moments ( $\mathrm{T}$ and $\mathrm{T}+10$ years).

In the $\mathrm{T}$ moment, $27.1 \%$ of the analysed psychologists experienced high levels of stress (levels 4 and 5). However, the mostly frequently referred stress level is the mean level (level 3 ), with 23.4\%; a national study done with psychology professionals likewise found that the highest percentage was also at level 3 (Gomes \& Cruz, 1999). In the T+10 moment, it was shown that $31.8 \%$ of the analysed psychologists $(\mathrm{N}=63)$ experienced high levels of stress (level 4 and 5), while, like the T moment, the mean level and most referred was level 3, with $28.8 \%$.

\subsection{Burnout evaluation}

Table 2 shows the predominance of Burnout in the psychologists.

The appraisal was done with the Portuguese adaptation of the MBI, keeping in mind that values above 2.6 in the Emotional Exhaustion dimension and 1.8 in Depersonalization, as well as values lower than 3.5 in the personal accomplishment dimension, are also indicators of high levels of Burnout. The obtained results show that a certain degree of psychologists experience high levels of Burnout:

- at Emotional Exhaustion level - T moment: $22.86 \%$; T+10 moment: $28.6 \%$

- at Depersonalization level - T moment: $2.29 \%$; $\mathrm{T}+10$ moment: $6.3 \%$

- at Diminished Personal Accomplishment - T moment: $11.43 \%$; T+10 moment: $17.5 \%$ The simultaneous combination of the results of the three dimensions - Emotional Exhaustion, Depersonalization and Diminished Personal Accomplishment - point to an average of $13 \%$ (T moment) and $17.5 \%$ (T+10 moment) of the psychologists exhibiting Burnout.

\subsection{Stress Generator Factors}

Table 3 shows the Stress Generator Factors. The appraisal was done taking into consideration 
the answers higher than 2.5 (out of a 5 point scale: 0 - no stress; 5 - plenty of stress) and that were frequent in more than $50 \%$ of the analysed population.

In the $\mathrm{T}$ moment, the following stress factors, grouped in 4 uneasiness generator factors, were identified according with the Cooper and Marshall (1977) model: a first group associated the intrinsic job factors - excess of work, lack of time to properly accomplish the professional tasks, worries and over involvement and excess of bureaucratic tasks. A second group, based on the relations established with superiors and supervisors, was comprised of the following: lack of experience; incompetence or rigidity of some supervisors; lack of guidance, supervision and encouragement by the supervisors. A third group associated to the role performed in the organization, included the following: negative and/or unwanted roles, making decisions where the mistakes can have severe consequences and implications, and consequences of the failures or mistakes that may occur. A fourth group, referring to the opportunities given by the organization, included the following: levels of career progression and achievement of the initial experiences and aspirations.

In the $\mathrm{T}+10$ moment, we have identified a first group associated to the intrinsic job factors: overload or excess of work, excess of bureaucratic tasks, lack of time to properly accomplish professional tasks, and working for too many consecutive hours. A second and final group limited to the opportunities given by the organization, includes the following: lack of perspectives for career development, failure to accomplish initial experiences and aspirations, living with the financial resources at my disposal and receiving a low salary when compared to other psychologists of my area of expertise.

\subsection{Coping Evaluation}

Table 4 shows the most common Coping strategies used by the psychologists. The outcome was obtained by averaging the sum of each item of each group of the coping strategies, divided for the total number of items of the same group.

The results show that the most used strategies are the control strategies ( $T$ moment: $M=3.46$; $\mathrm{T}+10$ Moment: 3.97), followed by the avoidance strategies, while the Symptoms Management Strategies are the least used (T moment: M=2.27; $\mathrm{T}+10$ Moment: 2.56). The use of the three coping strategies is more evident 10 years later, where the control ( $\mathrm{T}$ moment: $\mathrm{M}=3.46$; $\mathrm{T}+10$ Moment: $\mathrm{M}=3.97$ ) and the Symptoms Management Strategies are the ones that are more used by these psychologists $(\beta=0.15, p=0.005 ; \beta=0.39, p=0.002$, respectively).

\subsection{Most used coping strategies}

Table 5 illustrates a predictive behaviour of the Coping variables, keeping in mind Stress, Emotional Exhaustion, Depersonalization and Personal Accomplishment.

The Beta values were obtained by simple regression equation calculations, considering the stress, emotional exhaustion, depersonalization and personal accomplishment as independent variables and the coping strategies as a dependent variable.

Table 5 highlights that, in Stress situations, the most significant coping strategy used by the psychologists in the Algarve is Symptoms Management. We can easily see from the evaluation done by the psychologists from the Algarve that the Symptoms Management Strategy is seen as the most effective to deal with Stress. Over a period of 10 years (between 
$\mathrm{T}$ and $\mathrm{T}+10$ moments), the perception of this efficiency has become even more clear (from .366* to $.389^{*}$ ).

Likewise, we can see that, in Personal Accomplishment situations, the most significant strategy used by the psychologists from the Algarve is the control strategy either in the $\mathrm{T}$ moment $\left(.329^{*}\right)$ or in the $\mathrm{T}+10$ moment $(.312 *)$.

Table 6 describe the means related to Stress, Emotional Exhaustion, Depersonalization and Personal Accomplishment (in the Burnout context), Control Strategy, Escape and Symptoms Management (in the Coping Strategies context) bearing in mind the experience in the current job, in the first 2 years, from 5 to 10 years and more than 10 years, respectively. The higher values are the ones that are highlighted.

The results show that in the T moment, with between 2.5 and 5 years in the current job, the stress level is higher (39.93\%), coexisting with greater emotional exhaustion $(41 \%)$ and adopting Symptoms Management strategies (37.93\%). The Control Strategies are more used between 0 and 2 years (42.9\%); however, in the +10 years period, the Control Strategies are used again. The +10 years period is more characterized for depersonalization $(44.40 \%)$, diminishing of personal accomplishments (38.10\%) and adoption of escape strategies $(37.7 \%)$.

In the $\mathrm{T}+10$ moment, the highest stress level $(40.2 \%)$, greatest depersonalization $(43.45 \%)$, lowest levels of a sense of accomplishment (40.1\%) and the adoption of escape strategies are recorded. The Symptoms Management Strategies (39.53\%) are the most adopted ones in the period between 2.5 and 5 years in the job, and the Control Strategies $(39.23 \%)$ are the most adopted in the period between 0 and 2 years. However, in the +10 years period, they adopt the Control Strategies again.

10. Discussion of the results

Starting with the discussion by analysing the results about Stress, we have identified a large portion of psychologists who experienced stress ( $27.1 \%$ in $\mathrm{T}$ moment; and $31.8 \%$ in the $\mathrm{T}+10$ moment). These results are similar to the ones found in the psychologists at a national level (30\%) by Gomes \& Cruz (1999); in all the researches with psychologists, the distress levels are between 10 and $35 \%$. These values prove that psychology is not an exception among the other health care professions, despite their specific training and formation. It is, like all others professions, vulnerable to Stress. These results lead us to answer positively the starting question that we have formulated about the analysed psychologists showing high, global Stress levels in their professional practice.

Regarding the Stress Factors, we have seen that, in the T moment, they focus on aspects linked to intrinsic job factors. This work overload has been also seen in other investigations (Alvarez, 2003; Burden, 1988; Helman et al., 1986; Huberty \& Huebner, 1988; Manthei, 1987; Reiner \& Harstshore, 1982, et al.). This is why we think this is not a specific problem of the psychologists of the Algarve but a consequence of how their job is organized, both quantitatively and qualitatively. However, in the $\mathrm{T}+10$ moment, the intrinsic job factors are no longer the stress factor. This can be explained by Supper (1950), an author who studies career and profession development characteristics, who states that the development stage of worker permanency in the organization (which is the case of the evaluated psychologists in the $\mathrm{T}+10$ years moment) involves greater autonomy by the worker or the acceptance of 
responsibility (believing that he has some control over his career), having a greater timely perspective (better reflections over the past and anticipating an idea over the future) and a higher self-esteem (he believes that it is worthwhile planning for the future).

Another stress factor experienced by these psychologists in the $\mathrm{T}$ moment lay on the established relation with their supervisors in questions and related with the supervision. This factor is also identified in other studies (Burden, 1988; Deutsh, 1984; Reiner \& Harthore, 1982, et al.), highlighting that the lack of support and collaboration from the supervisors' side can lead to vulnerability and stress. The inflexibility, incompetence and lack of orientation from the supervisors are also patent in the Wise (1985) and Burden (1988) studies. The lack of experience shown by some supervisors was also highlighted by Boice and Mayers (1987) who pointed out the supervisor as a significant character and their lack and generator source of stress. In the T+10 moment, the established relations with superiors and supervisors is no longer a stress factor. Supper (1980) explains that this development stage (more advanced) is characterized by acquiring information, i.e., of relevant data about the labour market, which helps to put in perspective the results that can be achieved, ways and necessary actions. It is also a fertile stage to show the efficiency of making decisions using the available data, making possible for the psychologist to work with greater autonomy, with less supervision or just because, after 10 years of experience, he started to perform a supervisor's role himself.

Another kind of factor identified in the T moment is about the aspects related with the role played by the organizations. These results were also found by Cooper and Smith (2007), Simons (2006), Wise (1985), Huebner (1992), and Huebner and Mills (1997) concerning the excess of liabilities against the training received; this was also identified by Ockland and Cunningham (1992). The adoption of positions for negative and/or unwanted roles was also confirmed by the studies of Wise (1985), Burden (1989), Deutsh (1984), Rodolfa and Kraft (1988), and Hellman, Morrison and Abramowitz (1988).

This generator of uneasiness fact can eventually be related with the deficient support from the supervisors and from the organization itself, with the result that these psychologists need to assume tasks and responsibilities that they do not feel ready to perform or properly supervise. The role played by the organization is no longer a problem in the $\mathrm{T}+10$ moment, due to a more advanced development stage, which involves a greater exploration of attitudes by the workers in terms of asking questions about themselves and their situations in terms of the effective performance of the several roles played (Supper, 1980).

We have identified another kind of stress generator shared factors in the two evaluation moments ( $\mathrm{T}$ and $\mathrm{T}+10$ years), related with the opportunities offered by the organization.

This distress factor is also a problem that is shared by several Heath and Teaching professionals by not seeing their aspirations and ideals materialized and minimally satisfied. In the $\mathrm{T}+10$ moment, this factor, more than ever, is motivated by the current status of Portuguese politics and economic recession, which leads people to be more anxious about their safety and stability, not only regarding their jobs but also the development and fulfilment of their individual aspirations, which can be conductors of stress at work.

Regarding Burnout, the collected data, although not very serious, begins to be a little concerning by showing a certain number of psychologists from the Algarve who are at an end state of distress. $13 \%$ in the $\mathrm{T}$ moment and $17.5 \%$ in the $\mathrm{T}+10$ moment show Burnout. These 
results are similar to the ones of the national study (Gomes \& Cruz, 1999), in which $15 \%$ of the psychologists were in Burnout, and answers affirmatively to the starting question as to whether or not they show global Burnout levels in their professional practice.

Regarding the Coping Strategies (either in $\mathrm{T}$ and $\mathrm{T}+10$ moments), we can reach the conclusion that, like teachers (Jesus, 2002), the coping strategies most used by psychologists from the Algarve are the control strategies, followed by the avoidance ones; the symptoms management strategies are the least used. This allows us to answer the question, which is that the control strategies are the most used ones. Nevertheless, these psychologists think that the most effective strategies to deal with stress are the symptoms management strategies. From these results we conclude that, in a general way and in distress situations, the psychologists from the Algarve use adapted strategies, oriented toward problem solving, based on actions and proactive re-evaluations (control strategies), but they believe that the Symptoms Management strategy is the most effective to deal with stress. The control strategies most used by these psychologists are the kind such as: "giving their best to do what they think is expected of them", "thinking what changes can be done in that situation and speaking to other people involved", "dedicate more time and energy to do their job", and "try to see the situation as a learning opportunity and for the development of new competences".

Concerning the evolution with age, we can say in advance that, in the T moment, stress (39.93\%) and emotional exhaustion (41\%) are higher between 2.5 and 10 years of work, while, in the T+10 moment, they became more relevant after 10 years or more of work (stress, $40.2 \%$ and emotional exhaustion, $43.5 \%$ ).

In the more than 10 years of experience in the same job period, a higher depersonalization ( $\mathrm{T}$ moment, 44\%; $\mathrm{T}+10$ moment, 43.45\%) coexists with a decreasing of the sense of accomplishment (T moment, 38.10\%; T+10 moment, 40.1\%).

Concerning the coping strategies, the psychologists from the Algarve use the control strategies more (in the two evaluated moments) in the first two years of their current job, and, for this reason, it is evident that at the beginning of their activity they tend to have a more direct confrontation with the stressors. After 10 years they return to using the control strategies again. It seems that, after staying in the same job for 10 years regardless if they have higher or lower stress and exhaustion, it leads them to a more optimistic vision and makes them engage in a more direct confrontation with problems, while having a higher perception of efficiency and further adaptation. This factor seems to be more related with the professional development phase characteristics of these employees than with the stressors. Accordingly to Supper (1980), in this development stage the person should have an appropriate career maturity, i.e., is psychologically structured to continue the development of his career, in accordance with their expectancies in performing more relevant roles.

The Symptoms Management and Escape strategies are predominant in the two evaluated moments, between 2.5 and 10 years, regardless if it is motivated by a higher stress level ( $\mathrm{T}$ moment) or not ( $\mathrm{T}+10$ moment); choosing these Psychologists for a cognitivist re-formulation which could lead them to give up the problem solving strategies and embrace the emotions regulation and avoidance strategies is a fact that should be explored in the future. 


\section{Conclusions}

In the conceptual field, we committed ourselves to the clarification of the Stress, Burnout and Coping concepts by doing a review of the literature that was available to us. The psychology profession, like other health care and teaching professions, is vulnerable to Stress and Burnout, having negative effects, both professional and organizational. For this reason, Stress is a fundamental aspect and must be taken into account in any analysis which intends to take measures to promote lifestyles that lead to the well-being of these professionals. On the other side, we also tried to call attention to the existence of a large number of psychologists in the Algarve that show high Stress and Burnout levels. This fact raises the necessity of analysing what kind of measures can be taken to halt or prevent the spreading of this situation. It also became evident that these psychologists use good control strategies, proactive of problem solving. Nevertheless, they think the symptoms management strategies are most effective though they prefer the emotional regulation strategies. It seems to us that there is a tendency to use the same strategies that they recommend to their patients, in terms of healthy lifestyles. However, in high distress situations, they come back to the initial coping pattern, to the control strategies. In a slightly different perspective, we can verify that, in the T moment, the period between 2.5 and 10 years is the critical period where they adopt more symptoms management strategies. From 10 years, the renunciation to changing jobs and the decision to remain in the same work place seem to be in the origin of a return of the eustress, to a higher self-efficiency perception, facilitating the return of control strategies. This leads to a pro-active coping pattern that allows them a more effective adaptation to the job and greater personal accomplishment.

However, in the $\mathrm{T}+10$ moment, the +10 period in the job became the critical period, characterized for higher stress and exhaustion that may be motivated by the Portuguese economical and financial uncertainty, which favours the returning of the pro-active control strategies, as was done in the T moment. At last, we cannot finish without suggesting some intervention actions. One suggestion is the analysis of the way in which the psychologist job is organized, adding more variety, identity, significance, autonomy and feedback, making their jobs richer while avoiding their perception of overload, and helping them feel that they are capable of having greater control over their tasks and activities. In this way, prevention can play a relevant role at an individual, inter-personal and organizational level, which is conducive to strategies that promote a healthy lifestyle either to the psychologists or the organization. A common, modern example is the Burnout Workshops that are part of theoretical-practical sessions about the best ways to deal with stress in the workplace. These sessions comprise relaxation exercises, where the participants learn how to interpret problem-situations from different angles; they are informed about the influencing factors which underpin Burnout; they acquire social competences, get familiar with time management techniques, and are encouraged to have a healthy life style, extra-labour activities and individual careers (Maslach \& Schaufeli, 1993). There are, however, other measures that can be taken as an exhaustion prevention strategy, such as: self-esteem promotion, solid inner self, sharing with others (colleagues, supervisors, subordinates, clients, patients), active adaptation strategies (active listening of the emotions, knowing how to deal with the inter-personal conflicts, action planning, constructive reassessments, success 
acknowledgement and devaluation of failures, search for social support and trying to improve the work environment (Delbrouck, 2006).

Other ways to prevent and fight Burnout lie on the promotion of the professionals' commitment with the organization as a way to connect and identify with the organization for which they work. It means an increase of energy that the worker learns how to release in their duties and activities, greater involvement and self-efficiency (Maslach, 2001). We would not want to end without mentioning some of the limitations of a methodological and practical order related with the importance of the satisfaction and general well-being evaluation of the analysed psychologists, which could have received special attention. The small number of psychologists evaluated does not allow a representativeness which would enable generalizations. As clues for future investigations, we urge for the need to evaluate a larger number of psychologists to prepare and implement integrated prevention programs.

\section{Bibliography}

ALVAREZ,.M. A. (2003). Estrés Y productividad. Revista Odontologica Ejercicio Professional 4 (2). Disponível em: http://www.odontomarketing.com/art?8feb2003.brom. Acesso em 23 de Fevereiro de 2013.

BEEHR, T. A. \& MGRATH, J. E. (1996). The methodology of research on coping: conceptual, strategic, and operational level issues. In M. Zeidner and N. S. Endler (eds). Handbook of coping Theory, Research, Applications. New York: John Wiley \& Sons, Inc.

BOICE, R. \& MYERS, P. E. (1987). Wich setting in healthin and happier, academe or private practice. Professional Psychology: Research and Practice, 18, 526-529.

BURDEN, R. (1988). Stress and the School psychologist. School Psychology International, 9, 55-59.

BURDEN, R. (1988). Stress and the School psychologist. School Psychology International, 9, 55-59.

CHANG, E.M., HANCOCK, K.M., JOHNSON, A., DALY, J.\& JACKSON, D. (2005). Role stress in nurses:review of related factors and strategies for moving forward. Nursing and Health Sciences 7, 57-65.

COOPER, C. \& SMITH, M. (2007). Estilos de direccion In Enciclopedia de salud Y seguridad en el trabajo ( $3^{\mathrm{a}}$ ed. Pp. 34.39-34.40). Disponível em http://wwwnotas.es/publica/enciclo. Acesso em 23 de Fevereiro de 2013.

COOPER, C. L. \& MARSHALL, J. (1977). Understanding executive stress. A Petrocelli Book. New York. Princeton.

CORDES, C. \& DOUGHERTY, T. W. (1993). A review and an integration of research on job burnout. Academy of Management Review, 18 (4), 621-656.

DELBROUCK, M. (Coord) (2006). Sindrome de exaustão (burnout), Manuais universitários, 47. Lisboa: Climepsi.

GOMES, A. R. \& CRUZ, J. F. (2004). A experiência de stresse e burnout em psicólogos portugueses: um estudo sobre as diferenças de género, Teoria, Investigação e Prática, v. 9 (2), pp. 193-212.

GOMES, R. \& CRUZ, J. (1999). Estudo do stress e do burnout no exercício profissional da psicologia em Portugal. Centro de estudos em educação e psicologia. Universidade do 
Minho.

GRANT, S. \& LANGAN-FOX, J. (2007). Personality and the occupational stressor.strain relationship: The role of the big five. Journal of Occupational Health Psychology, 12 (1). Pp 20-33.

HUBERTY, T. J., \& HUEBNER, E. S. (1988). A national survey of burnout among school psychologists. Psychology in the Schools, 25(1), 54-61.

HUEBNER, E. S. \& MILLS, L. B. (1997). Another look at occupational stressors among school psychologists. School Psychology International, 18, 359-379.

HUEBNER, E. S. (1992). Burnout among school Psychologists: an exploratory investigation into its nature, extent and correlates. School Psychology Quaterly, 7, 129-136.

JACKSON, S. E., SCHWAB, R. L., \& SCHULER, R. S. (1986). Toward an understanding of the burnout phenomenon. Journal of Applied Psychology, 71, 630-640.

JEX, S. M. (1998). Stress and job performance. Sage Publications, London.

LATACK, JANINA C. (1986). Coping with Job Stress: Measures and Future Directions for Scale Development. Journal of Applied Psychology, vol. 71, ํo3, pp.377-385.

MANTHEI, R. J. (1987). School counselors and job-related stress. New Zealand Journal of educational studies, 22, 189-200.

MAROCO, J. \& TECEDEIRO, M. (2009). Inventário de Burnout de Maslach para Estudantes Portugueses. Psicologia, Saúde \& Doenças,10(2), 227-335. Retrieved from:http://www.scielo.oces.mctes.pt/pdf/psd/v10n2/v10n2a06.pdf.Acesso em 25 de Fevereiro de 2013.

MASLACH, C. \& JAKSON, S. E. (1986). The Maslach Burnout Inventorm Manual (2nd ed.) Palo Alto. CA. Consulting Psychologist Press.

MASLACH, C. \& SCHAUFELI, W.B. (1993). Historical and conceotual evelopment of burnout. In W. Schaufeli, C. Maslach \& T. March (Eds). Professional burnout. Recent developments in theory and research. Washington Taylor \& Francis.

MASLACH, C. (1993) Burnout: A Multidimensional perspective. In W. B. Schaufeli Maslach, C. \& T. Mark (Eds). Professional Burnout: Recente Developments in theory an Research. Washington: Taylor \& Francis.

MELO, B. T., GOMES, A. R. \& CRUZ, J. F. (1997). Stress ocupacional em profissionais de saúde e do ensino. Psicologia: Teoria, investigação e prática, 2, 53-71.

ÖRTQVIST, D., DRNOVSEK, M. \& WINCENT, J. (2006). The influence of coping strategies on new venture performance. Northern Innovation Research Conference, Oulu, Finland, December 8.

PAYNE R, FIRTH-COZENS J (1987). Stress in Health Professionals. New York NY, Wiley.

REINER, H. \& HARTSHORE, T. (1982). Job Burnout and the school Psychologist. Psychology in the schools, 19, 508-512.

SHELL, R. (2007). Medicion Y remuneracin del rendimento In Enciclopedia de salud Y seguridad en el trabajo ( $3^{\mathrm{a}}$ ed. Pp. 34. Disponível em http:// www.mtas.es/publica/enciclo. Acesso em 23 de Fevereiro de 2013.

SUPER, D. A. (1980). A life-span, life-space approach to career development. Journal of Vocational Behavior, 16, 282-298.

WISE, P. S. (1985). School Psychologist's rankings of stressful events. Journal of School 
Psychologist, 23, 31-41. 2013, Vol. 3, No. 2 


\begin{tabular}{ccccc}
\hline Stress level & \multicolumn{2}{c}{ Frequency } & \multicolumn{2}{c}{$\%$} \\
& T Moment & T+10 Moment & T Moment & T+10 Moment \\
0-no stress & 9 & 6 & $12.9 \%$ & $9,1 \%$ \\
1 & 11 & 8 & $15.7 \%$ & $12,1 \%$ \\
2 & 14 & 12 & $20 \%$ & $18.2 \%$ \\
3 & 17 & 19 & $24.3 \%$ & $28.8 \%$ \\
4 & 14 & 15 & $20 \%$ & $22.7 \%$ \\
5- plenty of stress & 5 & 6 & $7.1 \%$ & $9.1 \%$ \\
\hline
\end{tabular}

Table 1. Data related to the global stress levels experienced by the psychologists from the Algarve in their jobs in $\mathrm{T}$ and $\mathrm{T}+\mathbf{1 0}$ moments.

\begin{tabular}{|c|c|c|c|c|c|c|}
\hline \multirow[t]{3}{*}{ Subject } & \multicolumn{2}{|c|}{$\begin{array}{l}\text { Emotional } \\
\text { Exhaustion }\end{array}$} & \multicolumn{2}{|c|}{ Depersonalization } & \multicolumn{2}{|c|}{$\begin{array}{c}\text { Diminished Personal } \\
\text { Accomplishment }\end{array}$} \\
\hline & \multicolumn{2}{|c|}{ Higher than 2.6} & \multicolumn{2}{|c|}{ Higher than 1.8} & \multicolumn{2}{|c|}{ Higher than 3.5} \\
\hline & $\begin{array}{c}\text { T } \\
\text { Moment }\end{array}$ & $\begin{array}{c}\mathrm{T}+10 \\
\text { Moment }\end{array}$ & $\begin{array}{c}\text { T } \\
\text { Moment }\end{array}$ & $\begin{array}{c}\mathrm{T}+\mathbf{1 0} \\
\text { Moment }\end{array}$ & T Moment & $\begin{array}{c}\text { T+10 } \\
\text { Moment }\end{array}$ \\
\hline $\mathbf{N}$ & 16 & 18 & 3 & 4 & 8 & 11 \\
\hline Percentage & $22.86 \%$ & $28,6 \%$ & $4.29 \%$ & $6.3 \%$ & $11.43 \%$ & $17.5 \%$ \\
\hline
\end{tabular}

Table 2. Predominance of the Emotional Exhaustion, Depersonalization and Diminished Personal Accomplishment at the $T$ moment $(N=70)$ and $T+10$ moment $(N=63)$.

\begin{tabular}{|c|c|c|c|c|c|c|c|c|c|c|}
\hline \multirow[t]{3}{*}{ Questions } & \multicolumn{2}{|c|}{$\mathrm{N}$} & \multicolumn{2}{|c|}{ Frequency } & \multicolumn{2}{|c|}{$\%$} & \multicolumn{2}{|c|}{ Mean } & \multicolumn{2}{|c|}{ D.P. } \\
\hline & $\mathrm{T}$ & $\mathrm{T}+10$ & $\mathrm{~T}$ & $\mathrm{~T}+10$ & $\mathrm{~T}$ & $\mathrm{~T}+10$ & $\mathrm{~T}$ & $\mathrm{~T}+10$ & $\mathrm{~T}$ & $\mathrm{~T}+10$ \\
\hline & Moment & Moment & Moment & Moment & Moment & Moment & Moment & Moment & Moment & Moment \\
\hline $\begin{array}{l}\text { 57.A work } \\
\text { overload }\end{array}$ & 70 & 63 & 55 & 53 & $79 \%$ & $84.1 \%$ & 3.4 & 3.6 & 1.46 & 1.47 \\
\hline $\begin{array}{l}14 . \\
\text { Incompetence } \\
\text { or rigidity of } \\
\text { the supervisors }\end{array}$ & 70 & 63 & 53 & & $76 \%$ & & 3.4 & & 1.39 & \\
\hline $\begin{array}{l}\text { 53.Making } \\
\text { decisions were } \\
\text { the mistakes } \\
\text { have severe } \\
\text { consequences }\end{array}$ & 70 & 63 & 51 & & $73 \%$ & & 3.4 & & 1.38 & \\
\hline $\begin{array}{l}\text { 32. Lack of } \\
\text { time to rightly } \\
\text { accomplish my } \\
\text { professional } \\
\text { tasks }\end{array}$ & 70 & 63 & 53 & 48 & $76 \%$ & $76,1 \%$ & 3.3 & 3.4 & 1.28 & 1.51 \\
\hline The & 70 & 63 & 47 & & $67 \%$ & & 3.2 & & 1.33 & \\
\hline
\end{tabular}




\section{Macrothink Mnstitute ${ }^{\mathrm{m}}$}

\begin{tabular}{|c|c|c|c|c|c|c|c|c|c|c|}
\hline $\begin{array}{l}\text { implications } \\
\text { and } \\
\text { consequences } \\
\text { of mistakes } \\
\text { and failures } \\
\text { that I can } \\
\text { commit }\end{array}$ & & & & & & & & & & \\
\hline $\begin{array}{l}34 \text {. The lack of } \\
\text { perspectives in } \\
\text { career } \\
\text { development }\end{array}$ & 70 & 63 & 50 & 41 & $71 \%$ & $65,1 \%$ & 3.1 & 3.8 & 1.44 & 1.13 \\
\hline $\begin{array}{l}\begin{array}{l}12 . \\
\text { worries }\end{array} \text { and } \\
\text { my over } \\
\text { involvement in } \\
\text { my job }\end{array}$ & 70 & 63 & 52 & & $74 \%$ & & 3.1 & & 1.12 & \\
\hline $\begin{array}{l}3 . \quad \text { Being } \\
\text { supervised or } \\
\text { directed by } \\
\text { people with } \\
\text { low } \\
\text { professional } \\
\text { experience }\end{array}$ & 70 & 63 & 49 & & $70 \%$ & & 3.1 & & 1.36 & \\
\hline $\begin{array}{l}\text { 36. Adopting } \\
\text { unwanted or } \\
\text { negative } \\
\text { positions or } \\
\text { roles }\end{array}$ & 70 & 63 & 45 & & $64 \%$ & & 3.0 & & 1.41 & \\
\hline $\begin{array}{l}25 \text {. The excess } \\
\text { of bureaucratic } \\
\text { tasks }\end{array}$ & 70 & 63 & 47 & 52 & $67 \%$ & $82,5 \%$ & 3.0 & 3.5 & 1.31 & 1.34 \\
\hline $\begin{array}{l}10 . \quad \text { Not } \\
\text { achievement of } \\
\text { the initial } \\
\text { aspirations or } \\
\text { experiences }\end{array}$ & 70 & 66 & 52 & 49 & $74 \%$ & $77,8 \%$ & 2.9 & 3.9 & 1.28 & 1.27 \\
\hline $\begin{array}{l}\text { 33. The lack of } \\
\text { support and } \\
\text { encouragement } \\
\text { of the } \\
\text { supervisors }\end{array}$ & 70 & 63 & 46 & & $66 \%$ & & 2.9 & & 1.31 & \\
\hline $\begin{array}{l}\text { 19. The lack of } \\
\text { guidance or }\end{array}$ & 70 & 63 & 47 & & $67 \%$ & & 2.9 & & 1.37 & \\
\hline
\end{tabular}




\section{Macrothink}

International Journal of Human Resource Studies

ISSN 2162-3058

2013, Vol. 3, No. 2

\begin{tabular}{|c|c|c|c|c|c|c|c|c|c|c|}
\hline supervision & & & & & & & & & & \\
\hline $\begin{array}{l}\text { 21. Working } \\
\text { for too many } \\
\text { hours straight }\end{array}$ & 70 & 63 & 43 & 53 & $61 \%$ & $84,1 \%$ & 2.9 & 4.1 & 1.47 & 1.43 \\
\hline $\begin{array}{l}\text { 60. Performing } \\
\text { more } \\
\text { administrative } \\
\text { or bureaucratic } \\
\text { tasks than the } \\
\text { ones related } \\
\text { with } \\
\text { psychology }\end{array}$ & 70 & 63 & 44 & & $63 \%$ & & 2.9 & & 1.46 & \\
\hline $\begin{array}{l}\text { 35. Living with } \\
\text { the financial } \\
\text { resources at } \\
\text { my disposal }\end{array}$ & & 63 & & 54 & & $85,7 \%$ & & 4.2 & & 1.56 \\
\hline $\begin{array}{l}\text { 29. Receiving } \\
\text { a lower salary } \\
\text { than the other } \\
\text { psychologists } \\
\text { in my field of } \\
\text { expertise }\end{array}$ & & 63 & & 35 & & $55,6 \%$ & & 4.3 & & 1.43 \\
\hline
\end{tabular}

Table 3. Stress generator factors in $\mathrm{T}(\mathrm{N}=70)$ and $\mathrm{T}+10(\mathrm{~N}=63)$ moments.

$$
\text { Mean }
$$

Coping Strategies

T Moment $\mathrm{T}+10$ Moment

Control Strategies

3.46

3.97

Avoidance Strategies

2.51

2.57

Symptoms management Strategies

2.27

2.56

Table 4. Coping strategies most used in the $\mathrm{T}$ moment $(\mathrm{N}=70)$ and $\mathrm{T}+10 \mathrm{moment}$

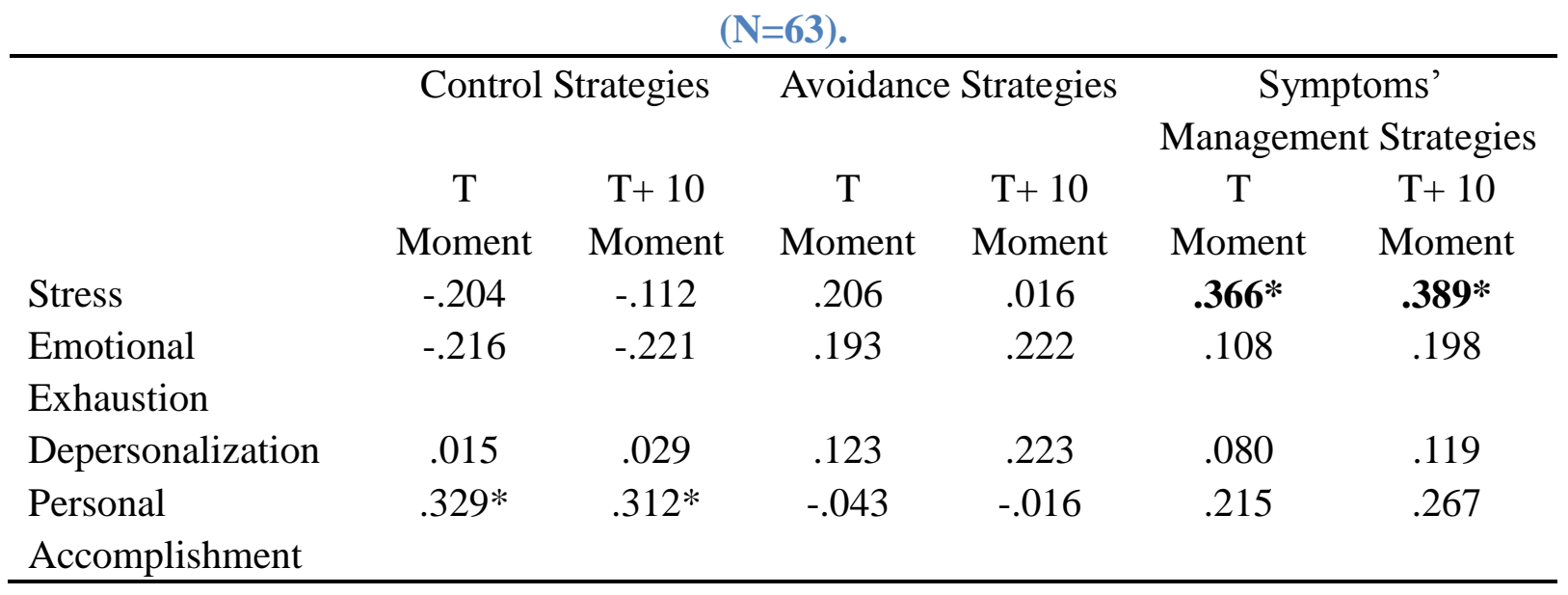

Table 5. Beta values obtained from simple regression equations in the $\mathrm{T}$ moment $(\mathrm{N}=70)$ and in the $\mathrm{T}+10$ moment $(\mathrm{N}=63)$. 


\begin{tabular}{|c|c|c|c|c|}
\hline & & (0-2 years) & $(2,5-10$ years $)$ & +10 years \\
\hline \multirow[t]{2}{*}{ Total Stress } & T Moment & 32.12 & 39.93 & 27.95 \\
\hline & $\mathrm{T}+10$ Moment & 22.6 & 37.20 & 40,2 \\
\hline \multirow[t]{2}{*}{ Emotional Exhaustion } & T Moment & 26.16 & 41 & 32.84 \\
\hline & $\mathrm{T}+10$ Moment & 21.3 & 35.2 & 43,5 \\
\hline \multirow[t]{2}{*}{ Depersonalization } & T Moment & 19 & 36.7 & 44.40 \\
\hline & $\mathrm{T}+10$ Moment & 21.45 & 35.1 & 43.45 \\
\hline \multirow[t]{2}{*}{ Personal Accomplishment } & T Moment & 37.2 & 34.24 & 38.1 \\
\hline & $\mathrm{T}+10$ Moment & 27.62 & 32.28 & 40.1 \\
\hline \multirow[t]{2}{*}{ Control Strategy } & T Moment & 42.9 & 17.0 & 40.1 \\
\hline & $\mathrm{T}+10$ Moment & 39.23 & 21.84 & 38.93 \\
\hline \multirow[t]{2}{*}{ Escape Strategy } & T Moment & 29.8 & 37.7 & 32.5 \\
\hline & $\mathrm{T}+10$ Moment & 29.9 & 39.88 & 30.22 \\
\hline \multirow[t]{2}{*}{ Symptoms' Management Strategy } & T Moment & 31.5 & 37.93 & 30.57 \\
\hline & $\mathrm{T}+10$ Moment & 30,01 & 39.53 & 30,46 \\
\hline
\end{tabular}

Table 6. Stresse, Burnout, Coping along the current job. 